\title{
Acquired haemophilia A after alemtuzumab therapy
}

Treatment with alemtuzumab leads to a prolonged depletion of T- and B cells, natural killer cells, dendritic cells and monocytes. ${ }^{1}$ Alemtuzumab therapy is associated with secondary auto-immune disorders, including auto-immune thyroid disease, immune thrombocytopenia and inflammatory neuropathy. ${ }^{1}$ Here, two patients with acquired haemophilia $\mathrm{A}(\mathrm{AHA})$ are described who were previously treated with alemtuzumab.

Patient 1 was a 24-year-old man who received a kidney transplant because of end-stage kidney disease caused by Alport syndrome. One year after transplantation, he was treated for a mixed-type kidney transplant rejection. He received methylprednisolone (total dose $3000 \mathrm{mg}$ ) and intravenous immunoglobulins $(2 \mathrm{~g} / \mathrm{kg}$ ) followed by alemtuzumab (30 mg, subcutaneously on two consecutive days). Four years after treatment for rejection, he presented with spontaneous bruising. He did not experience unintentional weight loss, fever, infection or night sweats. His immunosuppressive regimen at that time consisted of tacrolimus and prednisolone ( $5 \mathrm{mg} / \mathrm{d}$ ). Physical examination at presentation revealed multiple large haematomas on all extremities and on his thorax. Laboratory testing demonstrated an isolated prolonged activated partial thromboplastin time (aPTT) of 80 seconds (Table 1). The aPTT did not correct after mixing with normal pooled plasma (46 seconds). Factor VIII coagulation activity (FVIII:C) was strongly reduced $(0.02 \mathrm{U} / \mathrm{mL}$; normal 0.60-1.40 U/ $\mathrm{mL}$ ). A factor VIII inhibitor was confirmed and quantified with the Nijmegen modification of the Bethesda assay (10 Bethesda Units $[\mathrm{BU}] / \mathrm{mL}$; Table 1 and Figure $1 \mathrm{~A})$. Additional workup showed repopulation of T- and B-lymphocytes (Table 1). The patient was diagnosed with AHA and was treated with a single administration of activated prothrombin complex concentrate (factor eight inhibitor bypassing activity [FEIBA ${ }^{\circledR}$ ] $50 \mathrm{U} / \mathrm{kg}$ ) to stop bleeding of a severe bleeding in his arm resulting in pain and impairment of joint mobility of the elbow (Figure 1A). Immunosuppressive therapy was immediately started with prednisolone (1 $\mathrm{mg} / \mathrm{kg} / \mathrm{d}$, ie $80 \mathrm{mg} / \mathrm{d}$ ) and cyclophosphamide (100 mg/d). The aPTT shortened and FVIII:C increased within 2 weeks whereupon cyclophosphamide was discontinued (Figure 1A). The patient achieved complete remission of the AHA after 6 weeks with normalization of FVIII:C and no detectable factor VIII inhibitor (Figure 1A). Prednisolone was tapered to $5 \mathrm{mg}$ over a period of 6 months. Thereafter, prednisolone was continued $(5 \mathrm{mg} / \mathrm{d}$ ) as immunosuppressive therapy for the kidney transplantation.

Patient 2 was a 42-year-old man who received alemtuzumab (intravenously, $12 \mathrm{mg} / \mathrm{d}$ for 5 days and 1 year later $12 \mathrm{mg} / \mathrm{d}$ for 3 days) for relapsing-remitting multiple sclerosis. ${ }^{2}$ Fourteen months after the last dose, he presented with a large haematoma on his back after a dry needling treatment of the gluteus muscle without other complaints. He did not use any medications at the time of presentation. Physical examination revealed a large haematoma in the lumbar region which extended to his right upper leg, which was illustrated earlier. ${ }^{2}$ Laboratory testing revealed an isolated prolonged aPTT of 62 seconds which did not normalize after mixing with normal pooled plasma (54 seconds; Table 1). FVIII:C was strongly reduced (0.02 U/ $\mathrm{mL}$ ) and a factor VIII inhibitor was present (24.6 BU/mL; Table 1). The lymphocyte count was normal (Table 1). A diagnosis of AHA was made, and he was treated because of severe bleeding with a haemoglobin drop to $10.8 \mathrm{~g} / \mathrm{dL}$ with FEIBA ${ }^{\circledR} 100 \mathrm{U} / \mathrm{kg}$ on the first day followed by $50 \mathrm{U} / \mathrm{kg}$ two times daily for 6 days. He was also treated with prednisolone ( $1 \mathrm{mg} / \mathrm{kg} / \mathrm{d}$, ie $90 \mathrm{mg} / \mathrm{d}$ ) and cyclophosphamide $(200 \mathrm{mg} / \mathrm{d})$ as immunosuppressive therapy (Figure 1B). Complete remission of AHA was achieved after 6 weeks (Figure 1B). Cyclophosphamide was stopped 10 weeks after presentation, and prednisolone was tapered over a period of 7 months.

AHA is a rare auto-immune disorder caused by autoantibodies directed against factor VIII. It occurs mainly at (very) high age, or in young women after pregnancy. It is usually idiopathic (50\% of cases) but AHA may also be associated with malignancies, auto-immune diseases, infections, pregnancy and drugs. ${ }^{3-5}$ In our patients, additional investigations, including auto-immune serology

TABLE 1 Laboratory results

\begin{tabular}{|c|c|c|c|}
\hline Parameter & Patient 1 & Patient 2 & $\begin{array}{l}\text { Reference } \\
\text { range }\end{array}$ \\
\hline Haemoglobin (g/dL) & 10.3 & 10.8 & $13.7-17.7$ \\
\hline Platelets $\left(\times 10^{9} / \mathrm{L}\right)$ & 391 & 217 & $150-400$ \\
\hline Leucocytes (x109/L) & 15.6 & 5.8 & $4-10$ \\
\hline Lymphocytes (x10\%/L) & 0.84 & 0.80 & $0.50-5.00$ \\
\hline B-lymphocytes (x10\%/L) & 0.21 & - & \\
\hline T-lymphocytes (x10\%/L) & 0.63 & - & \\
\hline CD4/CD8 ratio & 3.9 & - & \\
\hline aPTT (seconds) & 80 & 62 & $25-31$ \\
\hline PT (seconds) & 11.3 & 13.1 & $9.5-13-5$ \\
\hline aPTT mix (seconds) & 46 & 54 & $25-31$ \\
\hline Factor VIII (U/mL) & 0.02 & 0.02 & $0.60-1.40$ \\
\hline vWF antigen $(\mathrm{U} / \mathrm{mL})$ & 1.79 & 2.31 & $0.60-1.40$ \\
\hline vWF activity $(\mathrm{U} / \mathrm{mL})$ & 1.67 & 2.94 & $0.60-1.40$ \\
\hline Bethesda VIII (BU/mL) & 10 & 24.6 & $<0.3$ \\
\hline
\end{tabular}

Note: Laboratory testing of the haemostasis parameters at presentation. Abbreviations: aPTT, activated partial thromboplastin time; PT, prothrombin time; vWF, von Willebrand Factor. 
(A)

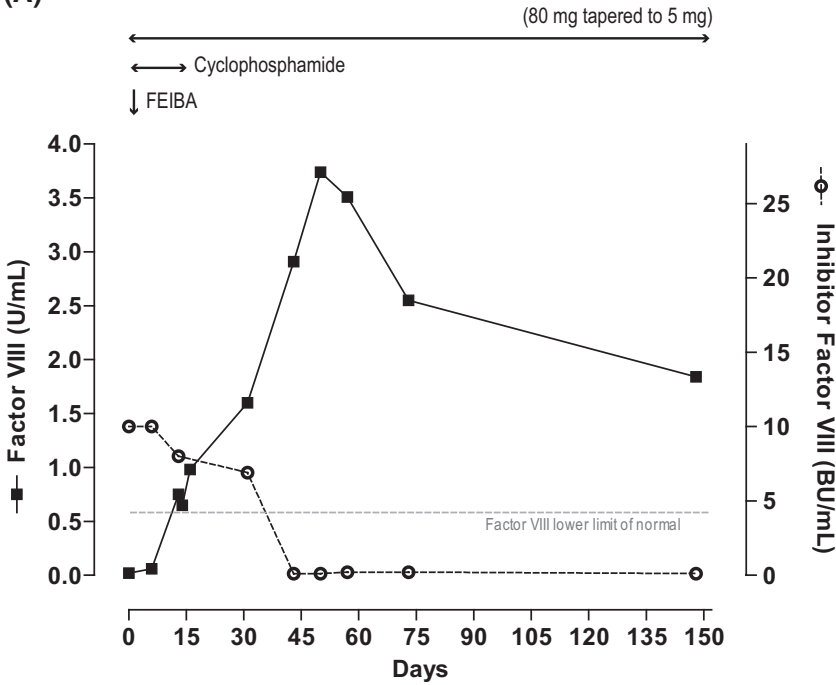

(B)



FIGURE 1 The concentrations of factor VIII and inhibitor of factor VIII in the first 6 mo of patient 1 (A) and patient 2 (B). The dashed line depicts the lower limit of normal of factor VIII. BU, Bethesda Units

(for systemic lupus erythematosus and rheumatoid arthritis), virology (of hepatitis B and C, and Epstein Barr virus) and a CT scan of the thorax and abdomen, did not reveal any underlying cause of AHA in our patients. There was no monoclonal gammopathy, white blood cell and platelet counts were normal, nor were there other signs of a haematological malignancy. Currently, both patients (three and one year after presentation) are still in remission of AHA after treatment with glucocorticoids and cyclophosphamide and no other auto-immune disorders or malignancies have occurred. ${ }^{6}$

In literature, an association between alemtuzumab and AHA has been described in four other patients. ${ }^{7-11}$ The indication for alemtuzumab was multiple sclerosis in three cases ${ }^{7-10}$ and antineutrophil cytoplasmic antibody-associated vasculitis in one case. ${ }^{11}$ The interval between alemtuzumab therapy and the diagnosis of AHA ranged from 11 months $^{9,10}$ to 5 years. ${ }^{8,11}$ Depletion of regulatory $T$ cells, natural killer and dendritic cells and escape of auto-reactive B cells after alemtuzumab therapy have been proposed to contribute to the increased susceptibility of secondary autoimmunity. ${ }^{1}$ Because of the lack of another explanation and the remarkable young age of our patients, we believe that AHA in our patients was related to the administration of alemtuzumab. Therefore, AHA should be considered in the differential diagnosis of an alemtuzumab-treated patients presenting with an acquired bleeding disorder.

\section{DISCLOSURES}

MvdZ declares no conflicts of interest. FWGL received research funding from CSL Behring, Shire/Takeda and uniQure. He is consultant for Biomarin, uniQure and Takeda of which fees got to the institution and is a DSMB member for Roche. MJHAK has received unrestricted research grants form Daiichi Sankyo, Boehringer Ingelheim, Bayer and Pfizer and speakers fee from Bayer. DAH has received grant support, lecture and consulting fees from Astellas Pharma and Chiesi Pharmaceuticals, as well as a lecture fee from Hikma Pharma and grant support from Bristol Myers-Squibb.

\section{AUTHOR CONTRIBUTION}

M.v.d.Z. wrote the article. The other authors critically revised and approved the final version of the manuscript.

$$
\begin{array}{r}
\text { Marieke van der Zwan }{ }^{1,2} \text { iD } \\
\text { Frank W. G. Leebeek }{ }^{3} \text { iD } \\
\text { Yorick Sandberg }{ }^{4} \\
\text { Marieke J. H. A. Kruip } \\
\text { (iD } \\
\text { Dennis A. Hesselink }
\end{array}
$$

${ }^{1}$ Department of Internal Medicine, Division of Nephrology and Transplantation, Erasmus MC, University Medical Center Rotterdam, Rotterdam, The Netherlands

${ }^{2}$ Rotterdam Transplant Group, Erasmus MC, University Medical Center Rotterdam, Rotterdam, The Netherlands

${ }^{3}$ Department of Hematology, Erasmus MC, University Medical Center Rotterdam, Rotterdam, The Netherlands ${ }^{4}$ Department of Internal Medicine, Maasstad Hospital Rotterdam, Rotterdam, The Netherlands

\section{Correspondence}

Marieke van der Zwan, Department of Internal Medicine, Division of Nephrology and Kidney Transplantation, Rotterdam Transplant Group, Erasmus MC, University Medical Center Rotterdam, Room Na-524, P.O. Box 2040, 3000 CA Rotterdam, The Netherlands. Email: m.vanderzwan@erasmusmc.n! 


\section{ORCID}

Marieke van der Zwan (iD https://orcid.org/0000-0002-9404-6135

Frank W. G. Leebeek (iD https://orcid.org/0000-0001-5677-1371

Marieke J. H. A. Kruip (D) https://orcid.org/0000-0002-0265-4871

\section{REFERENCES}

1. van der Zwan M, Baan CC, van Gelder T, et al. Review of the clinical pharmacokinetics and pharmacodynamics of alemtuzumab and its use in kidney transplantation. Clin Pharmacokinet. 2018;57:191-207.

2. Brink HS, Moll W, Sandberg Y. Acquired haemophilia A after alemtuzumab treatment of multiple sclerosis. $\mathrm{Br} J$ Haematol. 2020;190(1):13.

3. Kruse-Jarres R, Kempton CL, Baudo F, et al. Acquired hemophilia A: updated review of evidence and treatment guidance. Am J Hematol. 2017;92:695-705.

4. Knoebl P, Marco P, Baudo F, et al. Demographic and clinical data in acquired hemophilia A: results from the European Acquired Haemophilia Registry (EACH2). J Thromb Haemost. 2012;10:622-631.

5. Tengborn L, Baudo F, Huth-Kuhne A, et al. Pregnancy-associated acquired haemophilia $A$ : results from the European Acquired Haemophilia (EACH2) registry. BJOG. 2012;119:1529-1537.
6. Collins PW. Therapeutic challenges in acquired factor VIII deficiency. Hematology Am Soc Hematol Educ Program. 2012;2012:369-374.

7. Pisa M, Della Valle P, Coluccia A, et al. Acquired haemophilia A as a secondary autoimmune disease after alemtuzumab treatment in multiple sclerosis: a case report. Mult Scler Relat Disord. 2019;27:403-405.

8. Madeley J, Hodges G, Birchley A. Development of acquired haemophilia $A$ in a patient treated with alemtuzumab for multiple sclerosis. BMJ Case Rep. 2018:bcr2018226588.

9. McCaughan G, Massey J, Sutton I, et al. Acquired haemophilia A complicating alemtuzumab therapy for multiple sclerosis. BMJ Case Rep. 2017:bcr2017223016. htps://doi.org/10.1136/ bcr-2017-223016

10. Massey J, Barnett Y, Curnow J, et al. B cell depletion therapy resulting in sustained remission of severe autoimmune complications following Alemtuzumab treatment of Multiple Sclerosis. Mult Scler Relat Disord. 2019;35:100-103.

11. Clatworthy MR, Jayne DR. Acquired hemophilia in association with ANCA-associated vasculitis: response to rituximab. Am J Kidney Dis. 2006;47:680-682. 